This is an Accepted Manuscript of an article published by Taylor \& Francis

Julie Freeman, Sora Park \& Catherine Middleton (2019): Technological literacy and interrupted internet access, Information, Communication \& Society, DOI:

10.1080/1369118X.2019.1623901

To link to this article: https://doi.org/10.1080/1369118X.2019.1623901

\title{
Technological literacy and interrupted internet access
}

\author{
Julie Freeman ${ }^{\mathrm{a}}$, Sora Park ${ }^{\mathrm{b}}$ and Catherine Middleton ${ }^{\mathrm{c}}$ \\ ${ }^{a}$ School of Communication and Creative Arts, Deakin University, Australia; ${ }^{b}$ News \& Media Research \\ Centre, University of Canberra, Australia; ${ }^{c}$ Ted Rogers School of Management, Ryerson University, Canada.
}

\begin{abstract}
As everyday practices are increasingly digitalised, many countries are prioritising broadband rollout. However, infrastructure provision under national policies has not been uniform. In comparison to urban populations, rural communities often have inferior broadband infrastructure and services and there are disparities in digital opportunities between rural and urban areas. A case study of twenty rural Australian internet users reveals that rural communities suffer from limited access, inconsistent and unreliable services, and rural broadband plans' data restrictions and high prices, which we conceptualise as 'interrupted access'. Rural internet experiences are subsequently shaped by the availability, speed, stability and affordability of connections. As a response, a form of 'technological literacy' is emerging through which rural consumers undertake technical and social manoeuvrings to self-address challenges from interrupted access and increase their opportunities for digital inclusion. Participants developed innovative local solutions, such as self-installed auxiliary hardware and mobile towers, which they used to improve mobile broadband coverage. Those unable to build such solutions displayed new types of knowledge encompassing broader contexts of connectivity (infrastructure, devices and plans) and re-structured rural life to accommodate internet use that is shaped by interrupted access. Growing community-level capacity and interest in broadband development suggests national policies could better reduce rural-urban inequities by supporting and empowering localised solutions. Without addressing the interrupted nature of rural connectivity to improve service quality and affordability, disparities in the digital opportunities available to rural and urban consumers will persist.
\end{abstract}

Keywords: broadband infrastructure/services; digital divide; rural communities; digital inclusion

\section{Introduction}

In 2009 the Australian Government announced the construction of a National Broadband Network (NBN) to deliver ' $21^{\text {st }}$ Century Broadband' to all Australians (Government of Australia, 2009). A decade later, the NBN has been heavily criticised for failing to deliver promised superfast internet speeds. In rural Australia frustrations are reaching the breaking 
point as consumers grapple to stay afloat in the digital world despite inferior connections (Alizadeh \& Farid, 2017; Freeman, Fisher, Baum, \& Friel, 2018). The burgeoning inequities of broadband quality between rural and urban Australia bring risks of rural citizens facing new disadvantages that threaten their capacity to partake in and benefit from online opportunities.

Market failure is well recognised internationally as contributing to inferior rural broadband and mobile coverage (Ali, 2018; Barry, 2018). This situation has led governments to intervene to attempt to reduce spatial access disparities (Gerli \& Whalley, 2018; Salemink, Strijker, \& Bosworth, 2016). However, 'generic' national policies have been criticised for failing to solve rural-urban digital divides and assuming internet use is homogenous (Ali, 2018; Salemink et al., 2017). Multi-technology approaches to broadband provision mean rural communities are often supplied with inferior technologies to urban populations, which influences consumer experiences (Salemink \& Strijker, 2018). Internet use is shaped by specific place-based challenges (Philip \& Williams, 2019) that require consideration of the ways in which communities are impacted by and respond to any technological constraints within their spatial settings.

This article explores the everyday effects of inferior rural broadband on opportunities for digital inclusion. It has a dual goal of identifying challenges people face once using rural connections, and uncovering how they respond to these challenges to maintain their livelihoods in the digital era. This type of 'humanistic perspective' that seeks to uncover people's experiences and reactions is often overlooked in digital divide discourse that focuses on analysing policy and infrastructure deployment for rural communications (Ali, 2018; Donner, 2015). It is, however, necessary insight if future policy is to accommodate rural communities' needs and better address spatial disparities in broadband provision (Gerli \& Whalley, 2018; Philip \& Williams, 2019; Salemink \& Strijker, 2018).

This article examines the experiences of twenty internet users in households located in and around the rural townships of Boorowa and Crookwell, in the state of New South Wales (NSW), Australia. The term 'interrupted access' conceptualises how everyday internet experiences in these rural households are fundamentally shaped by limited service availability, inconsistent and unreliable service quality, and plans that cost more and offer less than services available in urban Australia. To overcome these challenges, users are displaying emerging forms of 'technological literacy'; a term we use to describe technical and social manoeuvrings to overcome the inadequacies of interrupted internet access. These include adopting local innovative solutions, such as self-installed towers and signal boosters, and developing and applying a deep awareness of how service conditions translate into direct and indirect usage costs. As urban infrastructure advances and society becomes more digitally-driven through data-intensive content, new approaches to address broadband quality differences are required for rural citizens to achieve digital inclusion. This article suggests there are opportunities and capacity for this to occur at the community level, if national policies better accommodate the particularities of rural contexts (Philip \& Williams, 2019; Salemink \& Strijker, 2018). 


\section{Rural-urban connectivity divides}

Internet access is increasingly vital for participation in social, economic, political and cultural practices (Gerli \& Whalley, 2018; Philip \& Williams, 2019). As the provision of broadband infrastructure has progressed, conceptualisations of the digital divide have evolved to reveal nuanced understandings of inequalities. Beyond access and digital skills, socio-economic, cultural and geographic circumstances impact opportunities for effective internet use (Philip \& Williams, 2019; Salemink et al., 2017). However, the form and quality of access still shape the activities undertaken online, and inequities often remain due to forced reliance upon expensive, unreliable, poor quality broadband outside urban areas.

Market forces have been insufficient in facilitating 'ubiquitous' broadband in many countries because the investment costs of network deployment in sparsely populated areas far outweigh the likelihood of profitable returns (Gerli \& Whalley, 2018; Salemink et al., 2016). Government policy interventions have subsequently attempted to reduce spatial disparities to ensure underserved and hard-to-reach communities have opportunities to participate in the digital economy (Gerli \& Whalley, 2018; Salemink et al., 2016). Often this is done through the supply of broadband technologies that are cost effective over distances, such as satellites and mobile towers rather than fibre-optics (Freeman et al., 2018).

Salemink et al.'s (2017) examination of rural digital development in advanced countries found that national policy approaches have not solved rural-urban divides because of a disconnect between the ideal of providing access to all and the challenge of achieving this goal. In particular, using multiple technologies creates bandwidth and speed differences, which bring policy implications for service equity (Liu, Prince, \& Wallsten, 2018; Stocker $\&$ Whalley, 2018). A broadband quality divide has since emerged where different infrastructure (and devices for connection) create diverged consumer experiences (Gerli \& Whalley 2018; Philip \& Williams, 2019). For this reason, there have been calls for more dynamic, customisable policy approaches to facilitate fit-for-purpose rural broadband through community-based developments that can accommodate place-based challenges (Philip \& Williams, 2019; Salemink \& Strijker, 2018).

In the Australian context, the NBN was intended to pre-empt the market failure of investment in broadband infrastructure by creating a government-owned company (NBN Co.) to build a network that would reach all Australians. The NBN uses a multi-technology mix including fibre-to-the-premises, fibre-to-the-node, fibre-to-the-curb, hybrid fibre coaxial cables, satellite, and fixed wireless technologies. ${ }^{1}$ The rollout has been slower and more expensive than planned (Alizadeh, 2015; Ryan, 2018) and retail prices are high for all service tiers. Five tiers of NBN connections are available to Internet Service Providers (ISPs), allowing them to offer speeds ranging from $12 \mathrm{Mbps}$ download and $1 \mathrm{Mbps}$ upload to $100 \mathrm{Mbps}$ download and $40 \mathrm{Mbps}$ upload. Inconsistencies in broadband technology have meant the goal of ubiquitous superfast internet in Australia remains unrealised (Alizadeh \& Farid, 2017; Freeman et al., 2018).

\footnotetext{
${ }^{1}$ See Freeman et al. (2018) and Alizadeh and Farid (2017) for detailed background on the NBN.
} 
Extensive research on Australia's broadband spatial disparities, for instance in the Australian Digital Inclusion Index (Thomas et al., 2017), highlights clear inequities between capital cities and rural areas, and identifies that the uneven distribution of infrastructure is widening rural-urban divides in digital inclusion (Alizadeh \& Farid, 2017; Freeman et al., 2018). Areas outside cities are predominantly served by satellite and fixed wireless technologies that offer maximum speeds of at best up to $25 \mathrm{Mbps}$ download and 5 Mbps upload. Compared with fixed-line broadband services, satellite and wireless connections bring a range of challenges that impact use (Donner, 2015; Freeman et al., 2018). These challenges are not just technical but also financial, as an absence of competition among ISPs keeps rural broadband prices high. The NBN has subsequently left many rural communities 'severely limited' for internet access (Department of Communications, 2013; Regional Telecommunications Review, 2015), and resulted in a paradox in that those who stand to benefit the most from advanced broadband are the least likely to be able to access quality connection methods (Salemink et al., 2017).

When rural areas are the last to receive quality high-speed infrastructure, spatial disparities create persistent challenges for digital inclusion (Alizadeh \& Farid, 2017; Philip, Cottrill, Farrington, Williams, \& Ashmore, 2017). As society becomes more reliant on dataintensive practices, rural-urban gaps will continue to widen and the opportunities afforded by digital technologies will become harder to achieve for rural consumers. New approaches to improve connection quality for hard-to-reach communities must be considered (Philip et al., 2017; Salemink et al., 2017). To inform such approaches, this article offers qualitative evidence of the state of internet access in a rural Australian area and illustrates how a number of residents are coping with poor quality, expensive broadband access.

\section{Case study background and methodology}

Understanding the changing nature of the digital divide requires detailed examination of specific contexts influencing internet access and use. The research for this article is part of a larger project investigating the varying circumstances of rural connectivity that started in Boorowa (population 1200), NSW, a predominantly agricultural community located just over $100 \mathrm{~km}$ north of Australia's capital city, Canberra. Previous fieldwork included a colloquium with local authorities to attain official views of NBN developments in the area, and a workshop with community leaders to explore how connectivity affects local socioeconomic development (Freeman, Park, Middleton, \& Allen, 2016; Park et al., 2015). This research extends these works to investigate everyday internet use in local residents' homes and small businesses. It draws from fieldwork conducted in Boorowa as well as the neighbouring township of Crookwell (population 2500), $85 \mathrm{~km}$ east of Boorowa (Figure 1).

While our research investigates rural connectivity, it is worth noting that Australian Government geographical classifications do not reflect 'rurality'. Instead, a combination of remoteness characteristics and road distances between populated localities and service centres are used to define differences between 'major cities', 'inner regional', 'outer regional', 'remote' and 'very remote' areas (Alizadeh, 2015). Both Boorowa and Crookwell are located near the outer edge of 'inner regional' Australia, which is identified as moderately accessible with regards to road distance measurements and nearest service centres (Figure 1). 


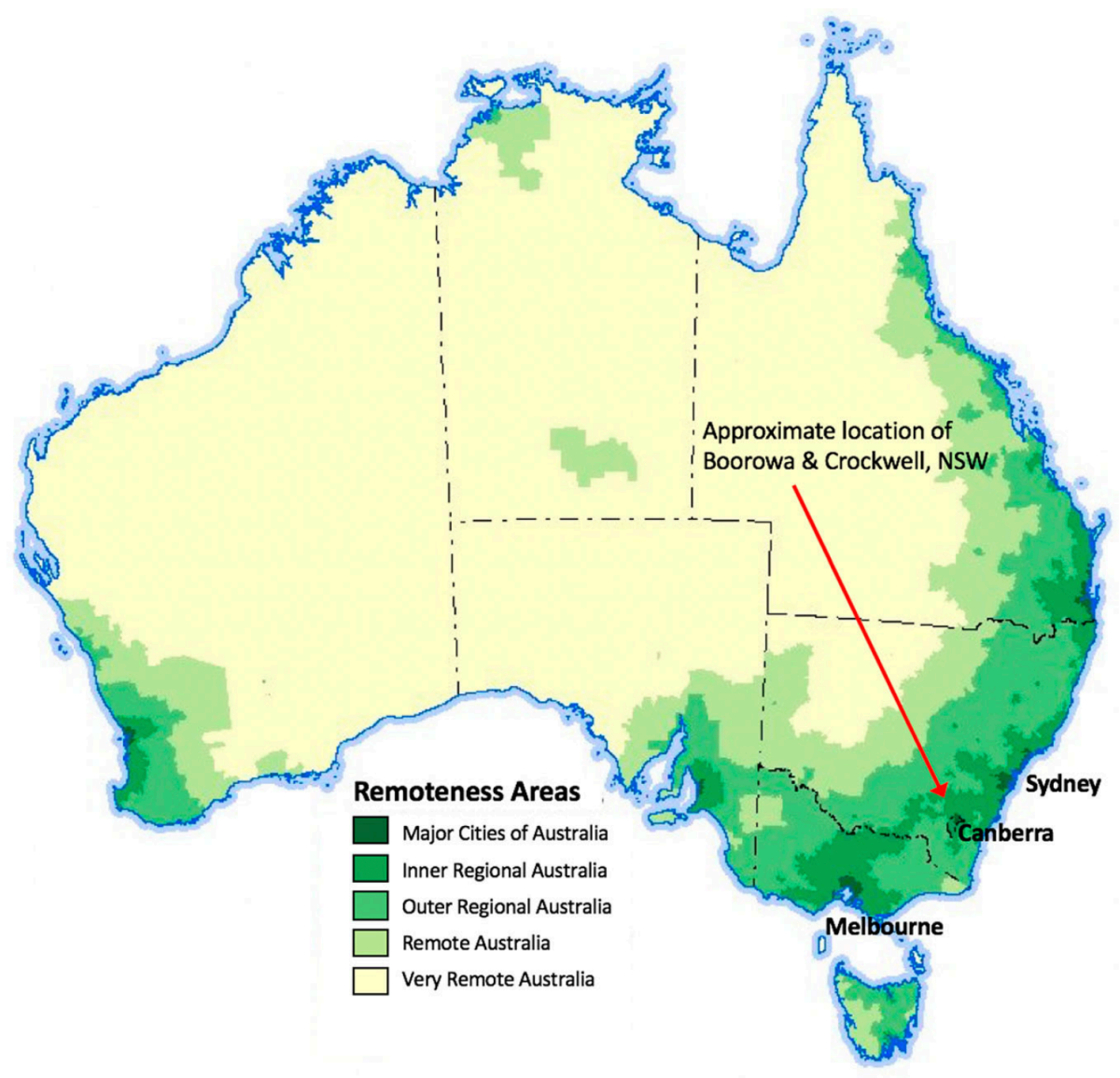

Figure 1. Australian Remoteness Areas (Australian Bureau of Statistics [ABS], 2016)

This geographical breakdown does little to facilitate understandings of the spatial challenges of digital infrastructure; travelling to access services defeats the purpose of connecting to the digital economy at home/work. As such, the figures provided here are intended only to highlight the location of the research sites. The remainder of this article considers these towns as 'rural' localities in line with other countries' definitions (Department for Environment, Food and Rural Affairs, 2016; Statistics Canada, 2001): Towns and surrounding areas situated outside the commuting zones of major cities/urban centres, with less than 10,000 residents and a low population density. Both Boorowa and Crookwell are agricultural communities with small populations and are not in close proximity to significant urban areas (outlined in red in Figure 2). 


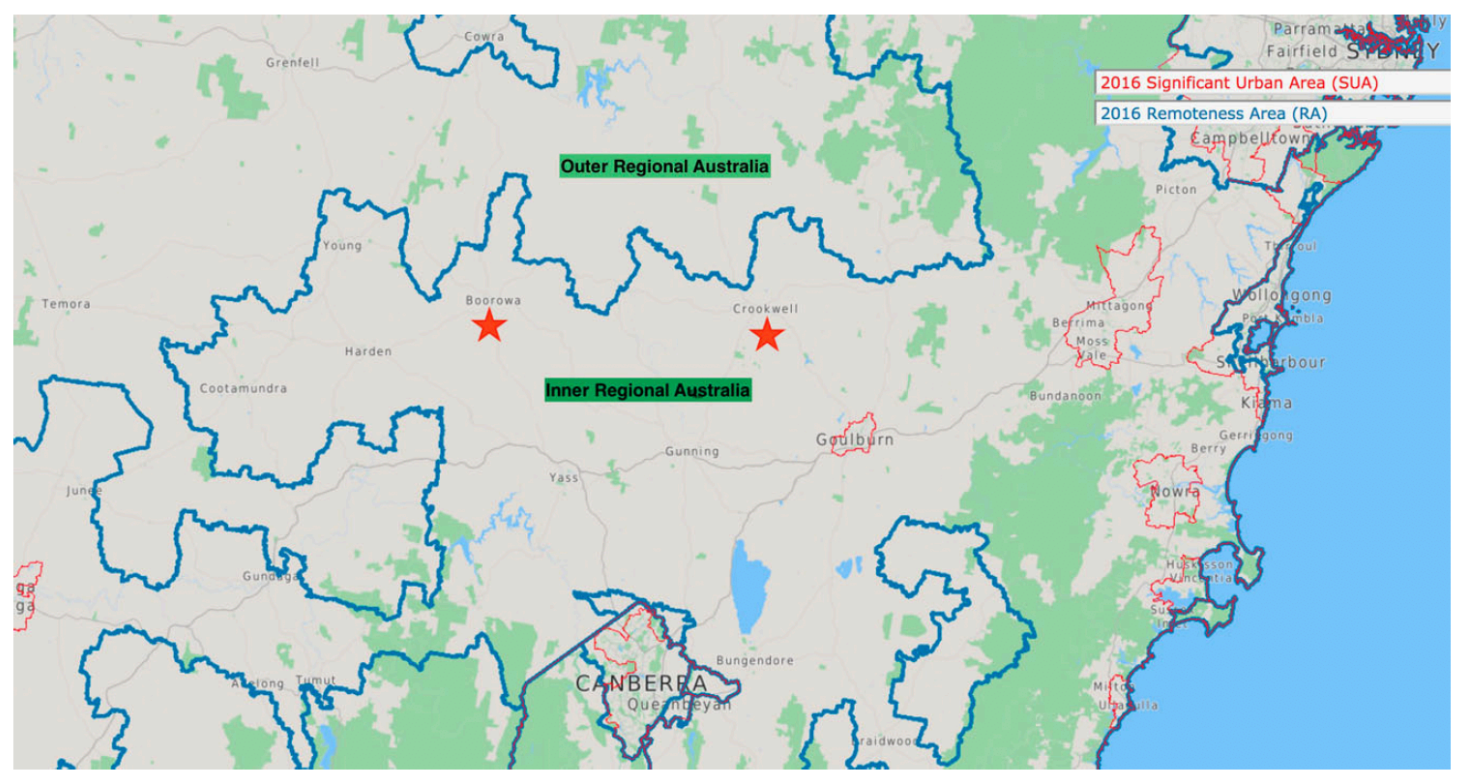

Figure 2. Location of Boorowa and Crookwell, NSW (ABS Maps, 2019)

ADSL broadband service (which uses the existing copper telephone network and delivers reliable but relatively slow service by 2019 standards) is available within the Boorowa and Crookwell townships, but there is currently no capacity available for additional users at the local exchanges. Broadband service is available from commercial mobile operators. Both towns' mobile towers were upgraded to $4 \mathrm{G}$ in mid-2016, and $3 \mathrm{G}$ reception (offering download speeds of between $550 \mathrm{kbps}$ and $3 \mathrm{Mbps}$, when using external antennas) is intermittently available for a couple of kilometres beyond the townships. There is a sizeable blackspot (an area with no mobile service) in between the towns and most of the surrounding farmland does not have mobile coverage. Rural residents outside the fixed wireless network footprint can connect to the NBN satellite service.

Interviews and focus groups were held in Boorowa and Crookwell to gain insight into the perspectives of socially-situated participants (Lindlof \& Taylor, 2011). Participants were initially recruited with the assistance of Hilltops Council, which governs 19,000 citizens across $7000 \mathrm{~km}^{2}$. The council disseminated a call for involvement from Boorowa residents through its community newsletter. News of the research then spread through word-ofmouth and participation snowballed to include residents from Crookwell as well as people from farmland surrounding the towns.

Twenty local residents participated in individual interviews or small focus groups (of two to three people) of approximately one-hour duration in November 2016 to discuss their digital experiences including connection challenges and common household/business internet uses. Recurring issues were identified during the interviews and focus groups, and then confirmed through thematic analysis of the transcripts. For anonymity, participants' names have been replaced with pseudonyms in this article. They are aged from their early $40 \mathrm{~s}$ to mid-70s and live up to $45 \mathrm{~km}$ from their nearest township. The majority are business owners (operating from their homes), predominantly in the agriculture industry. Table 1 outlines participant information as well as their type(s) of internet access at home/work. 
Table 1. Summary of Participants

\begin{tabular}{|l|l|c|c|c|c|}
\hline Pseudonym: & Education: & Age: & Gender: & $\begin{array}{c}\text { Distance (km) - } \\
\text { home to town } \\
\text { centre: }\end{array}$ & $\begin{array}{c}\text { Type of internet } \\
\text { access: }\end{array}$ \\
\hline Colin* & Bachelor Degree & 69 & M & 8 & Mobile/satellite \\
\hline Courtney* & Diploma & 49 & F & 25 & No response \\
\hline David* & No response & 46 & M & 15 & Satellite \\
\hline Dawn* & Year 10 & 50 & F & 15 & Satellite \\
\hline Graham* & Year 10 & 53 & M & 5 & Mobile \\
\hline Ivan* & Diploma & 67 & M & 16 & Mobile/satellite \\
\hline Joshua* & Diploma & 67 & M & 28 & Mobile \\
\hline Justin* & Bachelor Degree & 64 & M & 11 & Satellite \\
\hline Kacey* & Diploma & 49 & F & 45 & Mobile \\
\hline Liam* & Diploma & No response & M & 27 & Mobile/satellite \\
\hline Lily* & Bachelor Degree & 49 & F & 20 & Mobile/satellite \\
\hline Lisa & Diploma & 50 & F & 36 & Mobile/satellite \\
\hline Mark & Bachelor Degree & 61 & M & 20 & Mobile \\
\hline Mia* & Bachelor Degree & No response & F & 20 & Mobile/satellite \\
\hline Mitchell & Diploma & 62 & M & 20 & Mobile/satellite \\
\hline Penny & No response & No response & F & 27 & No response \\
\hline Preston & Year 10 & 75 & M & 14 & Mobile \\
\hline Ray & Diploma & 66 & M & 2 & Satellite \\
\hline Roger* & Diploma & 63 & M & 0 & ADSL/mobile \\
\hline Sara* & Year 12 & 43 & F & 25 & Mobile/satellite \\
\hline
\end{tabular}

* Participants who are business owners.

Poor connectivity in the area contributed to demand from local residents to be involved. While this demonstrates heightened awareness and concern for digital inclusion, it also presents an element of bias within our findings; those directly affected by inferior internet access were more likely to participate. It was, however, our intention to investigate the experiences of people who face difficulties connecting to the internet to uncover the impact on their everyday lives and learn how they are responding to these difficulties.

Approximately seven million Australians (nearly 30\% of the population) live outside major cities and the majority of these people will receive less-than-ideal broadband technology under the NBN (Freeman et al., 2018). Therefore, while the participants' views and experiences do not necessarily reflect those of all rural-living Australians, they do offer insight into some of the challenges that may arise as more geographically-dispersed communities are connected to different broadband technologies.

\section{Interrupted access and altered internet experiences}

Many dimensions of the digital divide traditionally attributed to non-use, such as literacy to use devices, did not factor in participants' responses. The overwhelming majority were adamant that they possess the necessary knowledge and skills to effectively use the internet, 
and that they own up-to-date devices with current software. Participants had a detailed awareness of the benefits of internet use, and recognised that society is becoming increasing connected and that everyday tasks now must often be completed online. However, there was considerable concern about rural-urban spatial inequities associated with NBN developments (Alizadeh, 2015; Freeman et al., 2018). Participants feared for their future in the digital world as they spoke of being 'forgotten' (Liam; Joshua) and 'lesser citizens' (Mitchell) because they are unable to partake in online opportunities to the same level as urban Australia:

As the world gets more and more reliant on this technology and these ways of communicating, I think it's a terrible thing that some sections of society are going to be alienated and disengaged... All Australians should have a chance at fast-speed internet and the technology as it develops, rather than the government concentrate on the cities of the eastern seaboard and let various other parts of Australia lapse behind. (Colin)

Like many rural Australian areas, these participants can connect to an 'internet of sorts' (Preston), predominantly through wireless technologies. This connectivity is characterised by the interrupted nature of access, as described below, and the digital inclusion challenges these participants face stem from the types of connections available, with service quality and affordability affecting what they can do online. Three interrelated themes subsequently emerged: limited internet access; inconsistent and unreliable services; and rural plans' data limits and pricing.

\section{Limited access}

Satellite and mobile broadband are the main forms of internet used by participants (see Table 1). Satellite services are physically tethered to premises, making the connection impractical for use on farmland, and restricted to one subscription per household. NBN satellite service, called Sky Muster ${ }^{2}$, was intended to provide rural-living Australians with improved internet access and relieve congestion caused by high-demand on the satellites already in service. However, Sky Muster deployment has been problematic (Barbour, 2016). Several participants argued it is inferior to the previous satellites and many potential users are yet to connect to the service. Sara, for example, connected to Sky Muster when it became available in mid-2016, but the service only lasted seven days before it 'crashed'. While her ISP's technician and another local technician both confirmed it was a signal issue (rather than hardware or software), Sara struggled to have the problem rectified:

It was this political handball between our internet provider and NBN over whose fault it was... NBN, we couldn't ring them direct... The internet provider didn't want to know me. It was a nightmare. I had to go to the Communications Ombudsman... Now we can't reconnect [for three months] because I've been connected.

\footnotetext{
${ }^{2}$ NBN Co. operates two Sky Muster satellites and consumers contract with an ISP of their choice to receive service.
} 
This was a common experience among residents who subscribed to Sky Muster soon after its launch. As knowledge of these types of issues spread through the community, others were hesitant to subscribe to the service: 'Needless to say, nobody has got NBN [Sky Muster] here after the first lump of people got it' (Courtney).

Mobile reception is largely limited to more-populated areas, and relies on sufficient line-ofsight to towers. ${ }^{3}$ The immobility of rural mobile broadband was evident as participants outlined topographical challenges. The area's hills and valleys make it difficult to maintain sightlines to towers; many spoke of intermittent reception and having to stand in certain locations to receive signals. Residents living in smaller townships such as Frogmore (population 380), Rugby (population 70) and Reids Flat (population 50) have no mobile coverage at all. The 'bleak, black hole' (Sara) between Boorowa in the west, Crookwell in the east and Reids Flat in the north has subsequently been dubbed by locals as the 'Bermuda Triangle' (Courtney) of communications. Several participants reminisced about the wider coverage of previous technologies: 'Years ago, all the phones were CDMA. It was great, worked perfect, and then they all changed to digital and the range just diminished so much' (David). Others noted that the range and signal strength around the towns had reduced since the mobile towers were upgraded to $4 \mathrm{G}$. In comparison to the previous $3 \mathrm{G}$ signals with a typical range of 60 to $120 \mathrm{~km}, 4 \mathrm{G}$ signals will only extend up to $5 \mathrm{~km}$ from a base station (Mobile Network Guide, 2014).

The impact of limited mobile access was noted particularly in relation to agriculture, the primary local industry. Roger argued poor connectivity contributes to farmers' difficulty in adapting to the digital world when farming practices are increasingly technologicallydriven. Sara highlighted that without $3 \mathrm{G}$ coverage in her paddocks, there are lost business opportunities (such as not receiving potential contract notifications) and she expressed concern about her farming business's future as fundamental tasks transition online. For example, a web-based programme is used to monitor livestock health, including information that must be provided to abattoirs. Without internet access, she cannot submit electronic stock declaration forms to send animals to market and will be unable to complete other activities as they become digital-by-default.

While urban Australians often have a range of connection methods and ISPs available, rural residents are rarely offered such choice. Several participants indicated they had been 'yoyos' (Mark) between ISPs, including changing to higher-priced plans to try to ensure some level of service. Ray, who lives only two kilometres from town, noted:

I go to Dodo [ISP] and nothing's working. I opted out of there pretty quick and went back to Telstra. I find with the main provider [Telstra], you get service. If you go outside it, there would be cheaper plans. The plans might be cheaper, but you're not getting the service.

Mia tried Optus (another ISP) for her mobile connection but was unable to receive signals and so she too returned to Telstra, Australia's incumbent fixed-line telecommunications

\footnotetext{
${ }^{3}$ As of 2015, mobile coverage extended to approximately 30\% of Australia's landmass (Regional
} Telecommunications Review, 2015). 
provider. Poor coverage therefore adversely affects rural consumer choice by removing options of cheaper plans (discussed below).

\section{Inconsistent and unreliable services}

Beyond connection challenges, participants are constrained by service quality, particularly in relation to reliability and speed. Graham, who runs a large agricultural business, commented:

It's just a constant struggle. You've got to keep resetting the thing and then hopefully you'll get a connection eventually. It's very unreliable... You're constantly interrupted. If you try and do something in the day time, like from lunchtime onwards, you have awful trouble.

Mobile signals drop out and speeds are slowed by a range of factors including congestion from simultaneous use. Participants were also aware that cloud cover, rain and wind, as well as local infrastructure (such as wind farms), interfere with satellite signals. Ray is often unable to connect three or four times a week, and indicated there can be 'a month where you get nothing at all.' Several noted that their mobile broadband slows down significantly when local school children return home and services overload, making it time consuming to complete basic tasks like banking online. These intermittent connections also inhibit use of data-heavy websites and audio/visual content streaming:

You can't get a continuous stream. Even though we've got a smart TV, we never use it because it's so frustrating. The only time you can, would be two, three o'clock in the morning, because it's obviously not overloaded then. (David)

Sara and Mitchell both expressed desire to stream catch-up television programmes from the nation's public service providers, but neither has yet been able to do so. As more programmes are integrated with online platforms or offered solely through streaming services like Netflix, people with limited connectivity are disadvantaged for content choice. Entertainment was, however, largely a secondary objective of internet use to these participants: 'The idea of them [government] constantly trying to improve things in the city so people can watch more Netflix or whatever - we just want to be able to run a business' (Lily).

Participants who use the internet for work were especially frustrated by slow and unreliable connections. Lisa uses Skype for audio-only meetings from her workplace in town, although noted its ineffectiveness and that she would be unable to use Skype at home 'because of the latency issue with the satellite'. David emphasised how slow speeds disrupt and delay his engineering business's everyday workflow, such as not being able to place orders and look up information online. Colin, a screenwriter, said his satellite connection drops out weekly. He argued, 'it's critical that I'm connected to Melbourne and Sydney producers... It would be much better for me if I had fast and dependable access'. Colin can upload and email screenplays through his Sky Muster service. However, instead of conducting virtual meetings, he drives for approximately two-and-a-half hours (one-way) to Sydney to talk with networks and producers. Like others, he is concerned that as the 
number of Sky Muster subscriptions increase, the speeds will decrease and he will be disadvantaged as his urban colleagues and competitors receive access to superior infrastructure.

Interestingly, these participants were not concerned about having 'always-on' internet access, as has become the common expectation and understanding of broadband in many urban locales (Barry, 2018; Liu et al., 2018). Instead, participants desired stable access with consistent speeds when they did connect. They also recognised that rural areas are generally associated with limited services:

I understand that the rural service is not going to be as good, I get that. But I object to having to pay so much more for a compromised service. You should be paying half the price of what other people are, if we're only getting half the service. (Lily)

Lily's comment highlights how spatial inequity not only involves broadband access and quality issues, but also concerns a perceived unfairness in relation to the additional economic costs imposed on rural consumers to use inferior infrastructure and services.

\section{Rural plans' data limits and pricing}

Data limits on rural plans inhibit internet use and contribute to the increased costs of connectivity. Limited data capacity and high costs were argued to be the 'biggest issue' (Mitchell) that several participants faced. Those with Sky Muster connections were predominantly using Activ8me, Australia's largest satellite NBN ISP, with standard speeds of up to $12 \mathrm{Mbps}$ download and $1 \mathrm{Mbps}$ upload. Participants noted that unlike most connection methods, satellite plans are divided into peak ( $7 \mathrm{am}$ to $1 \mathrm{am}$ ) and off-peak ( $1 \mathrm{am}$ to $7 \mathrm{am}$ ) times with different data allowances ascribed to each. Once limits are reached, speeds slow to a maximum of $128 \mathrm{kbps}$ until the following month and additional data cannot be purchased. Several participants opted for higher-priced satellite plans to avoid breaching data limits and having the speed decrease.

At the time of research, the largest Activ8me Sky Muster plan provided 60GB data (peak use) for $\$ 115$ per month. ${ }^{4}$ In comparison, a range of providers offered unlimited data packages in urban locales for approximately $\$ 60$ per month. In late 2017, NBN Co. increased its maximum peak monthly download allowance for Sky Muster subscribers to 150GB. Activ8me passed this change onto consumers in a plan with 150GB peak use for $\$ 125$ per month. However, NBN Co. warned that its satellites do not have the capacity for all subscribers to use that amount of data, and anticipated an average monthly cap of 45GB per subscription (Coady, 2017). As subscriptions are restricted to one per household, this suggests that congestion and latency issues will continue to constrain use, and for some consumers - such as households with multiple users - the increased allowance may still be insufficient. In terms of mobile broadband, the largest data allowance available through Telstra was 50GB per month for $\$ 160$. After that, data was charged at $\$ 10$ per extra GB.

\footnotetext{
${ }^{4}$ All financial figures are provided in Australian dollars (AUD).
} 
Participants operating small businesses face additional costs to get the internet service they need; for example, each month Lily pays over $\$ 400$ and Liam spends $\$ 240$. Liam runs a business dependent on digital technologies and programmes like Photoshop. He stated, 'We were on 6GB. For a graphic arts business, that's peanuts. They gave us $18 \mathrm{~GB}$ and then we went over... it cost me about $\$ 300$ [extra].' Liam's design projects usually take around 100GB. With poor uploading speeds and limited data, he saves projects to a DVD/USB to post to clients rather than emailing them. Liam also spoke of having to re-download incomplete content after signal loss, and how this increases the data used on his plan:

Your download cuts out, then if you start all over again, you're hit with a double whammy [of data use]... there's no guarantee that you're going to get through the next time.

Others noted how newer devices and software rely on the internet, such as cloud backups and Windows 10 updates, which further contribute to the expense of wireless plans. Lisa used her 4GB monthly allowance in one day before changing her network settings to recognise her satellite connection. She noted that this 'stops the automatic updates happening' but data is still used when periodically completing updates. Participants with children and multiple devices working off one connection found this situation challenging: 'We used our monthly usage in four days... Even though our limit is twice what it used to be, we're reaching the limit in half the time' (Lily).

For Lily, much of her home data use is due to the digital nature of her children's education. She noted they use online resources for schoolwork and submit assignments through Google Classroom. Several participants indicated their children were conscious of household data allowances and would refrain from using the internet for homework unless it was during non-peak times. Similar comments were made in relation to how deeply entwined digital tools have become in Australian tertiary education. Courtney spoke of her son struggling to finish his university degree through distance education because he is often unable to log onto his student portal to access course material and complete assessments. She further noted,

My son actually has gone off our [telephone] bill onto his own, and he's horrified every month when it comes back, and he just goes, 'How did it get to that? I'm paying $\$ 135$ for unlimited phone [calls] with $20 \mathrm{~GB}$ of data. How can I be going over?'

Liam and Penny have both kept landline telephones because they have no mobile service at home, and others indicated they would cancel their landlines if they had adequate mobile coverage. Many also highlighted that the most reliable provider for mobile coverage at home was not necessarily the best provider for when on the road/farm. The high costs of rural connections are subsequently compounded by having to use different providers for landline, mobile and satellite subscriptions:

When we first came here, and we got on the NBN, we were given a list of providers and none of them were Telstra, so we couldn't get a package... I had to get a separate one [plan] for the internet, a separate for the landline, a 
separate one for the mobile. It's more expensive for us to get communication here than it would be if we were in the city. (Mia)

All participants were aware of cheaper urban-based plans offering unlimited calls and data. Sara stated:

We just all would love to be on the same level playing field... When you see there's unlimited download data packages for $\$ 59$ a month... we just want to do our basic business and the kid's education, they are the most important... We just don't have the data allowance in rural Australia.

The data limits and costs imposed on these rural Australians inhibit fundamental tasks, particularly for business and education. In comparison to many urban consumers, these participants rarely used the internet for entertainment, social networking or personal ecommerce transactions - even when connections were stable enough - because these tasks are not seen as priorities. This suggests that inferior services and rural plans' pricing are contributing to different internet experiences between rural and urban Australians. It was clear, however, that these households would undertake a broader range of online activities if not for Australia's rural data drought.

\section{Novel forms of technological literacy}

Participants devised innovative technical solutions and acquired detailed knowledge of infrastructure, devices and plans to help overcome the challenges of interrupted access. These actions are not substitutes for systematic national efforts to increase digital inclusion but do serve to highlight the reality that long-term improvements will require a range of approaches including developing and supporting localised solutions (Gans, 2007; Philip et al., 2017).

\section{Technical adaptions to interrupted access}

Participants were fully aware that rural areas with small and dispersed populations do not offer economically-worthwhile prospects for ISPs. Without a strong business case for better connectivity, residents developed their own measures to improve access opportunities: 'It looks like it's gonna be on ourselves to upgrade, to update and get the latest technology, to leave the bureaucrats behind and do our own stuff' (Preston). One local solution has been the self-installation of auxiliary hardware including external antennas, repeaters and boosters to amplify digital signals from mobile towers. Liam spoke of how he amplifies signals previously lost in the shadow of a hill so that he can now receive coverage at home. Lily uses a repeater to improve signal strength within her home and this has meant that people visiting her can receive signals on their own devices and use data from their own plans rather than from her home account.

Other people have gone a step further to improve their digital line-of-sight by building external towers with signal repeaters:

What this gentleman is doing, and some others around the place as well, they're going to that farm up the hill from where he is in the valley, putting in a battery, 
and a solar panel, and a Wi-Fi antenna, and firing it [the signal] down into his house. (Preston)

Preston is involved in his town's Progress Association and advocates for these types of mobile broadband solutions to assist people with problematic Sky Muster upload speeds and ping (response) times. He was aware of smaller telecommunications companies in other areas, like Red WiFi in the state of Queensland, which have experienced success in developing local wireless networks by positioning transmitters on existing infrastructure such as sheds and silos (Barbour, 2016). Some of the smaller towns around Boorowa and Crookwell are considering this type of do-it-yourself approach to community broadband. Sara spoke of how the land owners around the remote township of Reids Flat (which has no mobile coverage) are wanting to install their own tower. She recognised that this would be an expensive venture for such a small community (population 50) but indicated that her community lacked any alternatives.

Several others said they would build their own solutions if subsidies were available like they are for other critical infrastructure. Courtney highlighted that, depending on locations and the type of signal amplification needed, even in-home boosters can be expensive (generally costing around \$1300) without financial assistance. Many participants questioned why rural people should have to incur these additional - often prohibitive costs for a fundamental service, particularly as rural Australians are already socioeconomically disadvantaged in comparison to urban populations (Alizadeh, 2015).

\section{Social adaptions to interrupted access}

Participants spoke of how they adapt internet use around rural pricing and data allowances. Since facing \$300 in excess data costs in one month, Courtney's family pools data from mobile devices once they reach the limit on their home broadband connection. Like others, she has developed a detailed awareness of the broader contexts of connectivity and how newer devices/software chew through data when set to update by-default:

I spend half of my day checking the devices are not updating automatically, and when we get to the 50GB, I have to turn the Wi-Fi off, and we can't use it because we can't afford the extra over the month.

Participants displayed considerable understandings of service conditions and the ability to translate terms such as Mbps and peak/off-peak data allowances into relative usage costs. Furthermore, they strategically plan their internet use to accommodate speed challenges and plan restrictions, effectively re-structuring rural life and work around interrupted connectivity:

I get $14 \mathrm{~GB}$ in bonus time, and then 4 in normal time. Normal time runs from one o'clock in the day to eleven o'clock at night, which is when you're going to use it for when the kids come home from school. If they want to do something [online] they've got to try and get up early in the morning before they go to school, or wait until a weekend morning and try and get it all done in bonus time. (Dawn) 
Graham will only download large files between 1 am and 4 am. David spoke of how his daughter adapted her final year of secondary education to allow for satellite speed and data limits: 'for her to do her studies she was getting up at all times. Sometimes I'd get up at five o'clock in the morning and she's up at the kitchen table, doing her stuff.' David's comment raises concern about how the next generation of rural participants in the digital economy will perceive the convenience of internet use, if the inequities of rural broadband are not addressed.

In place of the above type of time-shifting to accommodate speed/data limitations, other participants would often travel to areas with coverage to undertake online tasks: 'We were driving into Boorowa or into Young or up the road where they get good enough service that we could use the dongle and device' (Lily). Areas known to have coverage have become community settings for internet use. Kacey, Lisa and Lily all noted how local people frequently park their cars at particular points on roadsides because they are known signal spots. In comparison to most public Wi-Fi hotspots in urban locales where users have supplementary (usually free) internet access, these rural signal spots often act as primary spaces for local residents to undertake work (but still require network provider subscriptions and data).

Many participants would schedule time each day to drive to their nearest town or signal spot, often over $20 \mathrm{~km}$ away, to complete online activities like emailing and banking. Lily, for example, would 'put another two or three hours aside to go somewhere else to try and deal with that [online tasks].' Lisa commented that she often loses half-a-day driving elsewhere to use the internet, and noted that '[i]t sounds ridiculous, but that's what we've got to do in order to conduct a business.' For those unable to self-improve digital signal strength, the high direct costs of rural connectivity (service/plans) are intensified by a range of indirect costs (time/travel) that exacerbate the social and economic disparities experienced in rural communities.

\section{Conclusion}

Digital inclusion is shaped by the availability, quality and affordability of broadband. In rural Australia, where the population does not have access to the fixed-line, always-on and often unlimited services readily available in cities, internet use is constrained by speed, stability and cost issues. Reliance on satellite and mobile broadband inhibits many everyday online tasks, and ongoing concerns about limited data allowances and the costs of connectivity contribute to 'metered mindsets' (Donner, 2015) that influence how the internet is used. For example, the rural consumers who shared their experiences for this research - despite living only $100 \mathrm{~km}$ from Australia's capital city - are unlikely to stream entertainment programmes or shop online, but instead prioritise business and educational needs. As more data-heavy practices that are critical to education, business, health and government services are provided online-by-default, lacking seamless internet access will further disadvantage rural consumers.

By developing technological literacy these participants have technically and socially adapted to cope with the interrupted access they experience, making what technology is available to them better suit their needs. For instance, their knowledge extends beyond 
understanding of devices and the internet to include broader interrelated contexts of connectivity (infrastructure, hardware, software, plans, costs, and data). Some demonstrated an ability to manipulate and manoeuvre hardware and devices to improve the quality and reliability of their connections. Those unable to do so exhibited detailed awareness of service conditions and re-structured rural life around coverage, data allowances and peak/non-peak times.

However, technological literacy occurs because of interrupted access. Many rural Australians have been left with no choice but to attempt to self-address the fundamental bottleneck inhibiting their participation in digital society (Barbour, 2016; Mochan \& Bennett, 2019). But technological literacy cannot address all barriers to quality connectivity; participants in this research displayed genuine concerns about the pricing and data allowances of inferior rural services. The problem of better service packages not being offered outside urban areas is beyond consumer control and cannot be solved by even the most informed, technologically-sophisticated citizen. This is an area that warrants detailed scrutiny of ISPs and plans. ${ }^{5}$ Further public sector intervention may be necessary to better regulate rural pricing, data allowances and definitions of peak times, to mandate zero-rated access (that is, excluding access from data allowances) to government, education and health services, or to support rural users through subsidies for internet-related costs.

The findings in this article also highlight how broadband spatial inequities - and consumers' responses (such as purchasing additional hardware or driving to signal spots) can reinforce and exacerbate the social and economic disparities experienced by rural communities (Alizadeh, 2015; Freeman et al., 2018). These participants accepted many inconveniences of rural lifestyles but viewed access to quality, affordable broadband as a deepening disadvantage because it shapes their future in the digital economy. Similar concerns have emerged in other countries. For example, Philip and Williams (2019) argue that the viability of rural small businesses in the United Kingdom is jeopardised by access to fundamentally inadequate broadband infrastructure. Governments must recognise that the provision of different technologies creates different divides. New approaches to address persistent geographical inequities are needed, particularly given neither public nor marketbased approaches have yet remedied broadband spatial disparities (Gerli \& Whalley, 2018; Salemink et al., 2017).

Before the NBN was announced, Gans (2007) argued that broadband provision in Australia requires many local solutions because technologies, user requirements and investment costs fundamentally vary across localities. Community-focused initiatives should be systematically considered in future public policy so that national strategies empower and strengthen local solutions, to better address varying topography and communities' sociotechnical capabilities (Gans, 2007; Philip et al., 2017). While not without its challenges, community involvement in broadband development has been recognised internationally as a key factor in ensuring fit-for-purpose service provision to underserved and hard-to-reach communities (Gerli \& Whalley, 2018; Philip \& Williams, 2019; Salemink \& Strijker, 2018).

\footnotetext{
${ }^{5}$ In March 2019, the Federal Court fined Activ8me for false advertising of available speeds, data allowances and pricing (Wallbank, 2019).
} 
There are a handful of innovative grassroots developments in Australia. For example, a group of Western Australian farmers wanting to improve productivity (through smartfarming) partnered with a small ISP and received a State Government grant for \$277,500 to build a 4G small-cell network that covers fifty farms (Mochan \& Bennett, 2019). Improved federal support would encourage more of these types of local developments. In the communities examined here, there is evidence of the potential for localised solutions through growing interest and capacity to self-address barriers to digital inclusion. However, further research into other rural Australian communities would better inform future policy so it effectively addresses potential social and economic disparities that can arise through national approaches to broadband rollout.

As urban broadband speeds advance and society shifts towards digital-first and dataintensive applications, rural users with expensive, lower quality, less reliable connections face additional barriers to digital inclusion. Connectivity in rural Australia is characterised by the interrupted nature of access; differences in technologies and services bring different divides. Digital exclusion is entrenched when users are bound by access, reliability, speed, costs and data allowance constraints, while increasingly expected to complete everyday activities online. If disparities in broadband quality and affordability are not addressed, considerable differences in rural and urban internet experiences will continue to emerge.

\section{Disclosure statement}

No potential conflict of interest was reported by the authors.

\section{Funding}

Freeman gratefully acknowledges the philanthropic support for this research received from the Edward Wilson Estate. Park's contribution to this research was supported by a University of Canberra Faculty of Arts \& Design Collaborative Project Development and Dissemination Grant (2016). Middleton's involvement was undertaken, in part, thanks to funding from the Canada Research Chairs Program and was supported by the Social Sciences and Humanities Research Council (Canada) and Ryerson University.

\section{Notes on contributors}

Julie Freeman is Edward Wilson Research Fellow and Lecturer in the School of Communication \& Creative Arts at Deakin University. Her research explores how rural and regional media ecologies and variabilities in internet connectivity impact digital inclusion and local democratic engagement. [email: julie.freeman@deakin.edu.au]

Sora Park is the Associate Dean of Research at the Faculty of Arts \& Design and Associate Professor of Communication at the University of Canberra. Her research focuses on the impact of digital technology on communication, media and society. [email:

sora.park@canberra.edu.au] 
Catherine Middleton is a Professor at the Ted Rogers School of Management, Ryerson University and held a Canada Research Chair in Communication Technologies in the Information Society (2007-2017). Her research focuses on the development and use of new communication technologies, with specific interests in mobile devices and fixed and wireless broadband networks. [email: catherine.middleton@ryerson.ca]

\section{ORCID}

Julie Freeman http://orcid.org/0000-0002-7599-4105

Sora Park http://orcid.org/0000-0003-3082-314X

Catherine Middleton http://orcid.org/0000-0003-1296-2613

\section{References}

Ali, C. (2018). Thoughts on a critical theory of rural communication (CARGC Paper 7). Philadelphia, PA: CARGC Press.

Alizadeh, T. (2015). The spatial justice implications of telecommunication infrastructure: The socio-economic status of early National Broadband Network rollout in Australia. International Journal of Critical Infrastructures, 11(3), 278-296.

Alizadeh, T., \& Farid, R. (2017). Political economy of telecommunication infrastructure: An investigation of the National Broadband Network early rollout and pork barrel politics in Australia. Telecommunications Policy, 41(4), 242-252.

Australian Bureau of Statistics (ABS). (2016). The Australian Statistical Geography Standard (ASGS) Remoteness Structure. Retrieved from http://www.abs.gov.au/websitedbs/D3310114.nsf/home/remoteness+structure

Australian Bureau of Statistics (ABS). (2019). ABS maps. Generated from http://stat.abs.gov.au/itt/r.jsp?ABSMaps

Barbour, L. (2016, October 8). Data drought: Rural Australians find alternative ways to get online despite Sky Muster rollout. $A B C$ News. Retrieved from http://www.abc.net.au/news/2016-10-08/rural-australians-find-alternative-ways-to-getonline/7913328

Barry, T. S. (2018). Australian broadband regulation reviewed. Australian Journal of Telecommunications and the Digital Economy, 6(1), 134-155.

Coady, D. (2017, June 27). NBN to double Sky Muster download limits in bid to end rural 'data drought'. $A B C$ News. Retrieved from http://www.abc.net.au/news/2017-0627/rural-nbn-users-told-to-expect-plans-with-higher-data-caps/8655718

Department for Environment, Food and Rural Affairs. (2016). Rural urban classification. UK Government. Retrieved from https://www.gov.uk/government/collections/rural-urban-classification 
Department of Communications. (2013). Broadband availability and quality report. Canberra, ACT: Department of Communications, Australian Government.

Donner, J. (2015). After access: Inclusion, development, and a more mobile internet. Cambridge, MA: MIT Press.

Freeman, J., Park, S., Middleton, C., \& Allen, M. (2016). The importance of broadband for socio-economic development: A perspective from rural Australia. Australasian Journal of Information Systems, 20, 1-18.

Freeman, T., Fisher, M., Baum, F., \& Friel, S. (2018). Healthy infrastructure: Australian National Broadband Network policy implementation and its importance to health equity. Information, Communication \& Society. Advance online publication. doi: 10.1080/1369118X.2018.1434555

Gans, J. S. (2007). Looking local on broadband. Public Policy, 2(1), 10-24.

Gerli, P., \& Whalley, J. (2018, August). Fibre to the countryside: A comparison of public and community initiatives in the UK. In 29th European regional conference of the International Telecommunications Society (ITS): Towards a digital future: Turning technology into markets? Trento, Italy: ITS. doi: 10.2139/ssrn.3137164

Government of Australia. (2009). 21st century broadband. Retrieved from https://www.accc.gov.au/system/files/21st\%20Century\%20Broadband $\% 20$ \%20Brochure\%20-\%20low\%20res\%20web.pdf

Lindlof, T. R., \& Taylor, B. C. (2011). Qualitative communication research methods (3rd ed.). Thousand Oaks, CA: Sage.

Liu, Y-H., Prince, J., \& Wallsten, S. (2018). Distinguishing bandwidth and latency in households' willingness-to-pay for broadband internet speed. Information Economics and Policy, 45, 1-15.

Mobile Network Guide. (2014). Improving mobile signal. Southport, QLD: Powertec Telecommunications Pty Ltd. Retrieved from http://www.mobilenetworkguide.com.au/pdf/Mobile-Network-Guide-ImprovingMobile-Signal.pdf

Mochan, K., \& Bennett, M. (2019, March 17). WA farmers fed up with slow internet build their own network. ABC Great Southern. Retrieved from https://www.abc.net.au/news/rural/2019-03-17/farmers-build-own-internetnetwork/10909040

Park, S., Freeman, J., Middleton, C., Allen, M., Eckermann, R., \& Everson, R. (2015). The multi-layers of digital exclusion in rural Australia. In T. X. Rui \& R. H. Sprague (Eds.), Proceedings of the 48th Annual Hawaii International Conference on System Sciences (pp. 3631-3640). Kauai, HI: IEEE. 
Philip, L., Cottrill, C., Farrington, J., Williams, F., \& Ashmore, F. (2017). The digital divide: Patterns, policy and scenarios for connecting the 'final few' in rural communities across Great Britain. Journal of Rural Studies, 54, 386-398.

Philip, L., \& Williams, F. (2019). Remote rural home based businesses and digital inequalities: Understanding needs and expectations in a digitally underserved community. Journal of Rural Studies, 68, 306-318

https://doi.org/10.1016/j.jrurstud.2018.09.011

Regional Telecommunications Review. (2015). Unlocking the potential in regional Australia. Canberra: Commonwealth of Australia.

Ryan, P. (2018, August 31). NBN budget revised up again to $\$ 51$ billion as higher costs and slower revenue bite. $A B C N e w s$. Retrieved from https://www.abc.net.au/news/201808-31/nbn-cost-revised-up-to-51-billion-dollars/10187108

Salemink, K., \& Strijker, D. (2018). The participation society and its inability to correct the failure of market players to deliver adequate service levels in rural areas.

Telecommunications Policy, 42(9), 757-765.

Salemink, K., Strijker, D., \& Bosworth, G. (2016). The community reclaims control? Learning experiences from rural broadband initiatives in the Netherlands. Sociologia Ruralis, 57, 555-575.

Salemink, K., Strijker, D., \& Bosworth, G. (2017). Rural development in the digital age: A systematic literature review on unequal ICT availability, adoption and use in rural areas. Journal of Rural Studies, 54, 360-371.

Statistics Canada. (2001). Rural and small town Canada. Analysis Bulletin, 3(3), 1-17.

Stocker, V., \& Whalley, J. (2018). Speed isn't everything: A multi-criteria analysis of the broadband consumer experience in the UK. Telecommunications Policy, 42(1), 1-14.

Thomas, J., Barraket, J., Wilson, C., Ewing, S., MacDonald, T., Tucker, J., \& Rennie, E. (2017). Measuring Australia's digital divide: The Australian digital inclusion index 2017. Melbourne: RMIT University.

Wallbank, P. (2019, March 16). Internet provider Activ8me slapped with $\$ 250,000$ misleading advertising fine. Mumbrella. Retrieved from https://mumbrella.com.au/internet-provider-activ8me-slapped-with-250000-misleadadvertising-fine-569759 